Is a specific in its action on Schistosomum haematobium as it is in its action on the Leishman-Donovan body (Leishmaniasis).

The following is an account of a case treated by Dr. Nicola Malouf, now practising in Khartoum, with his notes. It is interesting because not only does it in a short account give the typical course of the progress of vesical bilharziosis under treatment with antimony tartrate, but it shows that, with due care, the remedy may be administered without the necessity of the patient lying in bed for a month, or, in fact, without his having to go to bed at all. In point of fact the case was treated in the out-patient room of a private practice. The patient was detained for a short time after the injection at the surgery, and lay down on his bed for the rest of the day of injection at home. He went about his business in the interval as usual.

Abbashur Musa, a native of Wad Medani, 20 years old, a cultivator, visited Dongola in the years 1912-13, and returned with blood in his urine. His urine was nearly half blood and half urine at the time injections commenced; it was neve clear. A sample was sent on August 13th, 1918, to the Wellcome I'ropical Research Laboratories, Khartoum, and heavy infection with ova of Schistosomum haematobium reported. The patient had tried many medicines, especially extract of male fern, but without any effect whatever. He had had no previous disease, and complained of nothing except his urine and of some swelling and pain in the right testicle which he attributed to the same disease.

\section{Method of Treatment.}

A stock solution of tartar emetic, gr. 1 in each 20 minims of distilled water, was prepared, and each 20 minims of this was distilled water, was prepared, and each 20 minims of this was mixed with 30 minims of sterilized normal saline solution before
injection. The antimony tartrate solation was always injected injection. The antimony tartrate solution was always injected
into the right median cephalic vein. The treatment was begun on August 15th, 1918 .

\begin{tabular}{|c|c|c|c|}
\hline Date. & & Dose. & Untoward Action or Result. \\
\hline $\begin{array}{l}1918 . \\
\text { Aug. } 15\end{array}$ & ... & $\operatorname{gr} \cdot \frac{1}{2}$ & Nil. \\
\hline . 17 & ... & gr.1 & Nil. \\
\hline " 19 & $\ldots$ & gr. $1 \frac{1}{2}$ & Cough moderate. \\
\hline .. 21 & ... & gr 2 & Severe cough. \\
\hline , 23 & ... & gr. 2$\}$ & Severe cough. \\
\hline . 25 & ... & gr.2ł & $\begin{array}{l}\text { Severe cough; patient stated urine clear for } \\
\text { the tirst time in the last four years. }\end{array}$ \\
\hline . 27 & ... & gr. $2 \frac{1}{3}$ & $\begin{array}{l}\text { Severe cough, eyelids and face puffy, appetite } \\
\text { lost, felt very weak, cold hands, pulse } 100 \\
\text { and weak. temperature } 98^{\circ} \mathrm{F} \text {. }\end{array}$ \\
\hline . 30 &... & $\mathrm{gl}^{2} .2$ & Same symptoms but mild. \\
\hline Sept. 3 & ... & gr 2 & $\begin{array}{l}\text { Patient was given gr. } \frac{1}{2} \text { codeine phosphate } \\
\text { thirty minutes before the injection; cough } \\
\text { not so troublesome. }\end{array}$ \\
\hline . 11 & $\cdots$ & gr. $2 \frac{1}{2}$ & $\begin{array}{l}\text { Cough very severe, puffiness of face and eyelids } \\
\text { returned, colour of face ash-like, cold sweat. }\end{array}$ \\
\hline . 15 & $\cdots$ & gr.2 & $\begin{array}{l}\text { Codeine gr. } 3 \text {, in three doses at half-hour } \\
\text { intervals before injection : cough moderate, } \\
\text { no other untoward action. }\end{array}$ \\
\hline , 20 & $\cdots$ & gr 2 & $\begin{array}{l}\text { Codeine as on previous occasion with same } \\
\text { result. Patient wanted to stop treatment } \\
\text { as he believed he was cured. }\end{array}$ \\
\hline Oct. 1 & ... & $\mathrm{gl}^{1} .2$ & No complaint of special interest. \\
\hline . 3 & $\ldots$ & $\mathrm{gr} .2$ & No complaint of special interest. \\
\hline . 7 & $\ldots$ & $\mathrm{gr} .2$ & No complaint of special interest. \\
\hline.$\quad 12$ & $\ldots$ & $\mathrm{gr}^{2} .2$ & $\begin{array}{l}\text { No complaint of special interest. The last } \\
\text { injection. }\end{array}$ \\
\hline 'Total & ... & gr. 31 & \\
\hline
\end{tabular}

It will be seen (1) that for five years the patient had had haematuria, that his urine was never clear during four of these five years. (2) That after the fifth injection the blood in the urine disappeared and the patient stated that it was the first time for four years that his urine had been clear. (3) That after the twelfth dose the patient was convinced that he was cured; he may have been, but the course was continued by Dr. Malouf until he had given gr. 31 , in fifteen doses varying from gr. until he had given gr. 31 , in fifteen doses varying from gr: $\frac{1}{2}$ to
gr. $2 \frac{1}{2}$, in fifty-six days. The urine, owing to the exigencies of

private practice, was not tested every day. of eight days and ove of ten days. These lapses did not ap of eight days and one of ten days. These lapses did not apparently make any difference to the final result, and it is inSpanish influenza, so that in a man with healthy organs, Spanish influenza complicating the course of injections of antimony tartrate need have no untoward result.

The cases treated at the Khartoum Civil Hospital have the urine microscoped every day. The urine of the case being reported here has been tested half a dozen times since the injections ceased; it contained nothing abnormal. I am quite aware that a sufficient interval has not elapsed in the present instance to make any statement regarding the permanency of the cure, but no drug which $I$ know of has even the temporary effect on the subjective and objective symptoms of bilharziosis that antimony given as antimony tartrate has; this effect is certainly profound and striking.

In the only post-mortem examination I know of-in a case which had died during a course of treatment by anti. mony tartrate injections for bilharzia- 1 am informed that no worms were found in the portal circulation (the post-mortem examination was made a very few hours after death). This is an interesting and important statement and significant.

I have elsewhere ${ }^{2}$ drawn attention to the care and judgement necessary in dealing with a disease by the use of a powerful remedy such as antimony tartrate. It should be remembered that it is a poison, that even small quantities have been known to cause death (gr. $\frac{1}{2}$ in a child, gr. 2 in adult), to say nothing of the risk of chronic antimony poisoning, that the injection is made directly into the veins, and its use requires additional care by reason of this fact.

Intercurrent diseases of the heart, liver, kidneys, lungs, should be looked for, and the metabolic processes of the body so far as possible should be sound; if not normal, they are additional causes for circumspection.

I think gr. 30 should be considered for the present the maximum dose for an adult's course for bilharyiosis, and, if more be required, a second course of injections should be administered after an interval of some weeks or months. It may be that, as more is done on this treatment, a much smaller dose will be found to be the required killing "charge." It may be, and very likely is, the case that some cases only require a comparatively small dose whilst others require a dose of gr. 30 or more, and that others again require several courses of gr. 30 to rid them of the bilharzia worms.

It is almost certain that tartar emetic will have a deleterious effect on organs and tissues when given recklessly, empirically, and without the sense of responsibility which is due to the act of injecting anything-however benign, however poisonous-into another human being's veins.

There are still sufficient empirics in the medical profes. sion to damage again the reputation of tartar emetic (antimony) as a valuable remedy. Such a result would be a calamity now that it appears to be taking its proper place as one of the most powerful and useful germicidal agents we possess; and I think this note of warning is necessary, because it is in partially civilized countries where the diseases-leishmaniasis, sleeping sickness, and bilharziosis-which are amenable to treatment by antimony abound. There also the methods of the quack and charlatan flourish, encouraged by the ignorance and prejudice of the native races." I beg to acknowledge with thanks the help I have received from Mr. J. R. Newlove in this work.

REFERENCES.
1 Lancet, September 7th, 1918. 2 Jourm. of Trop. Med. and Hygiene, October 15th, 1917

\section{FIBRONA OF THE TRACHEA. BY}

JAMES B. HORGAN, M.B., Ch.B., HONORARY LARYNGOLOGIST TO THE NORTH OHARITABLE INFIRMARY, CORK.

Fibromata of the trachea, though they occur second in frequency amongst all innocent tumours found in this region, are nevertheless, I think, of sufficient rarity to justify the publication of such a remarkable case as that about to be described.

StClair Thomson ${ }^{1}$ states that fibromata of the tracheal lumen occur second in frequency to papillomata, but Sauer ${ }^{2}$ has only been able to collect published records of

* In the tropics there is a diversity of medical talent, as one would expect from the diversity of the nationalities of the doctors. In the eyes of the tropical public doctors are all the same. They are medinot the others. Most of the locsl doctors are is revealed to one and their way's of treatment, and the treatment of kala-azar in the Sudan (by antimony tartrate) has, no doubt, not come up to expectation in their hands. This is, however. no reflection on the efficacy of the
treatment when carried c ut intelligently. 
twenty-nine cases, which fact amply demonstrates the extreme rarity of such tumour's in the trachea.

The patient, P. S., aged 9 years, was sent to me by Dr. Harrington of Tralee with the provisional diagnosis that he was suffering from an intratracheal tumour. One of his brothers had died of diphtheria at the age of 8 years. The family history was otherwise irrelevant. The personal history was that with the exception of an attack of bronchopneumonia five years previously the boy had always enjoyed robust health until he had contracted measles three months ago. Since then he had had irregular attacks of dyspnoea, which, having increased in severity, especially at night, necessitated his being taken to the doctor two weeks before I saw him.

As his respiratory difficulty failed to yield to palliative treatment after one week, the advice of a throat specialist was recommended, but was not sought until a week later, by which time the urgency of the boy's condition had become very acute.

When I saw him on August 10th the patient presented all the clinical signs of almost total tracheal occlusion. He was unable to walk unsupported, his face was livid and anxious, and his voice very feeble but clear. His pulse was accelerated and feeble. There was orthopnoea and marked stridor, especially during inspiration. The lowe sternal and costal cartilages, as well as the upper abdominal parietes and suprasternal notch, were in a state of permanent and very decided retraction.

No breath sounds could be heard with the stethoscope in either lung, but a loud vibratory sound was audible ove the upper central sternal region. Upon examination the pharynx and larynx were seen to be normal. Examina tion of the trachea carried out by means of the Avellis procedure enabled me to see what appeared to be a dusky red, globular tumour, situated very low down in the trachea.

It was evident that immediate relief was necessary, but that any attempt to remove the tumour by upper direct tracheoscopy would under the existing condition of the patient be highly inadvisable. I accordingly decided to perform a low tracheotomy, and hoped thereby that if $I$ were unable to effect a removal of the tumour at once I would at least gain a respite.

General anaesthesia being out of the question, $I$ in filtrated the skin with novocain-adrenalin solution and proceeded to do as low a tracheotomy as possible. After exposing the trachea, and whilst in the act of ligaturing a large vein which crossed my intended tracheal incision, the patient suddenly lost consciousness and ceased to respire. An assistant at the same time informed me that the radial pulse was absent. I had artificial respiration adopted and pituitrin injected hypodermically whilst I immediately stabbed the trachea. I now found that the tumour mass lay below the longest tracheotomy tube available, but as natural though very laboured breathing had returned I had time to improvise a further course of action.

'The tracheotomy tube was removed, and holding the tracheal rings apart with a small self-retaining mastoid retractor I inserted a small Luc's nasal forceps in the direction of the bifurcation, grasping and removing a liard pediculated tumour. Breathing at once became easy and consciousness returned.

'The tracheotomy tube was left in, a few deep and superficial sutures uniting the soft parts above it, but was reinoved the next morning. As the patient's general condition rapidly improved I decided to make a lower tracheobronchoscopic examination. This was carried out five days after the removal of the tumour, the original wound being reopened for the purpose. The examination was carried out under ether-chloroform anaesthesia, $\frac{1}{2} \frac{1}{6}$ grain of atropine sulphate having previously been given hypodermically. 'The site of origin of the tumour was easily veritied on the anterior tracheal wall immediately above the bifurcation and cauterized by a very localized application of trichloracetic acid.

The patient made an uneventful recovery, and returned home within a week of this examination.

Upon macroscopic examination the removed tumour was found to be bilobular, the two portions being united at their base and lying together so as to form a globular mass, which was approximately the size of a small cherry. It was dusky red in colour, of fairly hard consistence, and the common pedicle was distinctly evident. Dr. Brönte, to whom the specimen was sent for microscopic examina. tion, reported that it was a fibroma, and consisted chiefly of fibrous tissue and blood vessels covered by compound epithelium.

I am inclined to the opinion that the tumour lay straddlewise across the bifurcation of the trachea and that any air reaching the lungs did so across the upper and posterior surface of each lobe of the tumour. Apart from the site of origin of the pedicle and the findings at operation, the size of the tumour when viewed en masse was such as to preclude the possibility of the patient living any time had the tumour occupied the trachea alone. Brünings ${ }^{3}$ states that from his investigations carried out in vivo he finds that the tracheal diameter in childrenand by children he expressly states that he means about ten years of age-varies between 8 and $11 \mathrm{~mm}$. The smallest diameter of the tumour referred to above was $1 \mathrm{~cm}$. In this respect I think that my case is unique amongst the sparsely reported cases of tracheal fibromata. For an innocent tumour a further very unusual if not singular feature of this case was the anterior attachment of the tumour pedicle. Woods reports a somewhat similar case of a non-pediculated innocent tumour in a boy aged 11. In this case the growth, which was reported to be "a round-celled growth with many blood vessels and apparently granulation tissue," had its origin from the right wall of the trachea immediately above its bifurcation. Woods succeeded in removing his tumour piecemeal by upper direct tracheoscopy under general anaesthesia, but the general condition of his patient was never serious. In both cases the symptoms were of not more than a few months' duration, though in my case it must be assumed that the tumour in some form must have been present for a much longer period, and it is interesting to note that it was apparently unaccompanied by dyspnoea or other symptoms until after the attack of measles.

Thomson ${ }^{1}$ states that tracheal tumours occur most frequently on the posterior wall, and that their frequency diminishes as the tube descends. From the records of published cases-both benign and malignant-I am not inclined to agree with the latter part of this statement, and am rather of the opinion that whilst the subglottic region is most frequently affected the lower end is affected next in frequency, and that the middle region is the least likely to be involved. Theisen ${ }^{6}$ remarks that tracheal tumours grow most frequently from the posterior wall, which is rich in mucous glands. This writer further says that owing to the relatively high proportion of tracheal tumour's-which he estimates at about 50 per cent. of the total-which prsie to be malignant, a strong suspicion of malignancy should always be attached to a tracheal tumour.

Guise ${ }^{6}$ reports the successful removal per vias naturales of two tracheal fibromata the pedicles of which were attached posteriorly.

Adam ${ }^{7}$ reports the case of an epithelioma about half the size of a cherry with a broad base growing from the tracheal wall just above and half obscuring the right bronchus, which he removed through a low tracheotomy wound.

Heymann ${ }^{*}$ records the case of a carcinoma growing from the anterior tracheal wall to the right of its union with the right bronchus.

Ioritz Schmidt ${ }^{2}$ in his textbook mentions the reports of three cases of tracheal fibromata, one of which was re moved through a tracheotomy wound, but he is not specifio as to their sites of attachment.

\section{REFERENCES.}

1 Diseases of the Nose and Throat, second edition, 1916, p. 590 2 Laryngoscope, vol. xviii, 1908, p. 252. 8 Die directe Laryngoscopne, Bronchoscopie und Oesophagoscopie, 1910, S. 223. * Journal of Laryngology, vol. Xxviii, No. 10. 5 Trans. Amer. Laryng. Assoc. paryngology, rol. xxx, No. 2. \& Zeitsch, fome Laryng., Bd. vi, Heft. Laryngology, rol. xxx, No. 2. 8 Zeitsch. f, Laryng., Bd. vi, Heft.5. S. 644 .

TILL recently there were only two medical schools in the Argentine Republic, at Buenos Aires and Cordoba, but a third has now been established at La Plata.

THE Indian Medical World, Calcutta, has published a chart of pathogenic bacteria for the use of candidates for the M.B. examination. It appears to have been prepared with care, and may no doubt be of use to students who have diligentiy followed a course of bacteriology. 